\title{
Wound management and vaccination following animal bite: a study on knowledge and practice among people in an urban area of Pondicherry, India
}

\author{
Bijaya Nanda Naik*, Swaroop Kumar Sahu, Ganesh Kumar S
}

Department of Preventive and Social Medicine, JIPMER, Pondicherry, Tamilnadu, India

Received: 09 August 2015

Accepted: 20 August 2015

*Correspondence:

Dr. Bijaya Nanda Naik,

E-mail: drnnbijaya @gmail.com

Copyright: ( ) the author(s), publisher and licensee Medip Academy. This is an open-access article distributed under the terms of the Creative Commons Attribution Non-Commercial License, which permits unrestricted non-commercial use, distribution, and reproduction in any medium, provided the original work is properly cited.

\section{ABSTRACT}

Background: Correct wound management and vaccination following animal bite prerequisite for prevention of rabies. Objective: To find out knowledge and practice about the correct wound management and vaccination following animal bite among the individuals in a selected urban area of Pondicherry.

Methods: This explorative study was conducted in the field practice area of a tertiary care institution in urban Pondicherry. A total of 156 individuals one each from 156 households were selected and included after obtaining verbal informed consent. Using a pretested semi structured questionnaire, we obtained information on knowledge about wound care following animal bite and vaccination against rabies, and details of animal bite to any household members anytime in the past.

Results: Only $19 \%$ of the respondents could name "Rabies" as the cause of death following animal bite. All the respondents had known about immediate initiation of anti-rabies vaccine following animal bite and its free availability in government hospitals. However, only one third of the respondents were aware of immediate washing of wound with soap and water following animal bite. The last one year incidence of animal bite was found to be $0.87 \%$ (6/682). Majority of the animal bite cases belonged to Class II (58\%) and, involved dogs (88\%), males (79.2\%) and people from low socio-economic status $(96 \%)$. All the individuals with animal bites had initiated anti-rabies vaccine within 24 hours of bite, however only two third had washed their wound with soap and water immediately following animal bite. About $17 \%$ of the animal bite victims had applied oil or turmeric over the wound.

Conclusions: Incorrect immediate wound care following animal bite is a concern for prevention of rabies in this area. Health education should be strengthened on certain aspects like disease causation, wound care following animal bite and before coming in contact with a health facility to this population.

Keywords: Wound management, Animal bite, Rabies, Anti-rabies vaccine

\section{INTRODUCTION}

Wound management in animal bites is an important prerequisite in prevention of rabies. The concern on animal bite is common especially in developing countries since the beginning of the human civilization. The bites by dogs, cats and monkeys carry a huge public health burden in terms of mortality and morbidity and can lead to rabies, a disease which is $100 \%$ fatal and preventable. ${ }^{1-}$
${ }^{4}$ Globally, an estimated 55000 people die of rabies annually and more than half the deaths were because of the bites by rabid dogs. ${ }^{1}$ A WHO sponsored multicentre study from India reported the annual incidence of animal bite to be $1.7 \% .^{5}$

There is a lacunae among the people in the community to adopt correct wound management practices. ${ }^{5}$ Many other studies also reported low awareness on correct wound 
management practice following animal bite. ${ }^{6-8}$ The awareness about availability of anti-rabies vaccine varies from $86 \%$ to $95 \% .^{6,8}$ In a study from rural Maharashtra (2013) as high as $60 \%$ of the individuals were reported unaware of free availability of anti-rabies vaccine in government hospitals. Misconception and lack of awareness on wound management can lead to increased risk of developing rabies following animal bites. ${ }^{4}$ With this background, we planned the present study to find out awareness and practice about the wound management following animal bite among the individuals in a selected urban ward catered by a tertiary care institution in Pondicherry, India.

\section{METHODS}

We conducted an explorative study during April 2012 in a purposively selected urban ward (Kurusukuppam) attached to an urban health centre (UHC) of a tertiary care institution. This urban health centre caters to nearly 9000 population spread over four urban wards namely Kurusukuppam, Vazhakulam, Chinnayapuram and Vaithikuppam. UHC provides comprehensive primary health care to the whole population residing in the four wards which are similar in terms of socio-demographic factors and culture.

A convenient and consecutive sample of 156 households from the urban ward (Kurusukuppam) was taken for the present study because of feasibility. The study was conducted as a part of interns training program on community based research in the field practice areas of urban health centre. The household was included in the study after obtaining verbal informed consent from the head. In case of a household found locked during visit or refusing to participate, immediate next household was included after obtaining verbal informed consent. The trained interns paid house-to-house visits to the enrolled households and interviewed the wife of the head of the households and in her absence any adult member available during the visit using a pretested semi structured questionnaire. Only one adult individual from each household was included in the study. However, all household members were considered for calculation of incidence of animal bite. The information on sociodemographic details, knowledge about occurrence of rabies following animal bite, immediate wound care, availability and time of administration of anti-rabies vaccine following animal bite were noted. Further, history of animal bite to any household member in the preceding one year from interview or anytime in the past was obtained from the respondent. In case of positive history on animal bite, the detailed information of the victim, the animal, the wound, immediate care of the wound practiced and vaccination history against rabies were captured using the structured questionnaire. The data were entered in MS Excel and descriptive analysis was done using SPSS Version 16. One year incidence of animal bite was calculated and reported.

\section{RESULTS}

A total of 156 respondents were contacted. Approximately $90 \%$ of the respondents interviewed were females. Maximum numbers of respondents were aged 30 -44 years $(38 \%)$ and had completed only middle school (40\%). About $42 \%$ of the respondents belonged to Class $\mathrm{V}$ of Kuppusamy's socio-economic classification (Table 1).

Table 1: Socio-demographic details of the respondents from Kurusukuppam an urban ward of Pondicherry $(\mathrm{N}=156)$.

\begin{tabular}{|c|c|c|c|}
\hline Variable & Category & Frequency & Percentage \\
\hline \multirow{2}{*}{ Gender } & Male & 14 & 9 \\
\hline & Female & 142 & 91 \\
\hline \multirow{4}{*}{ Age (years)* } & $15-29$ & 14 & 9 \\
\hline & $30-44$ & 59 & 37.8 \\
\hline & $45-59$ & 41 & 26.3 \\
\hline & $\geq 60$ & 42 & 26.9 \\
\hline \multirow{6}{*}{ Education } & $\bar{N}$ No formal education & 21 & 13.5 \\
\hline & Primary school certificate & 28 & 17.9 \\
\hline & Middle school certificate & 62 & 39.7 \\
\hline & High school certificate & 17 & 10.9 \\
\hline & Higher secondary school certificate & 24 & 15.4 \\
\hline & Bachelor or master degree & 4 & 2.6 \\
\hline \multirow{5}{*}{ Socio-economic class (SES)** } & Class I & 5 & 3.2 \\
\hline & Class II & 18 & 11.5 \\
\hline & Class III & 20 & 12.9 \\
\hline & Class IV & 47 & 30.1 \\
\hline & Class V & 66 & 42.3 \\
\hline
\end{tabular}

2012) 
Table 2: Details of animal bite cases among the study population of Kurusukuppam an urban ward of Pondicherry $(\mathrm{N}=\mathbf{2 4})$.

\begin{tabular}{|c|c|c|c|}
\hline Variable & Category & Frequency & Percentages \\
\hline \multirow{2}{*}{ Gender } & Male & 19 & 79.2 \\
\hline & Female & 5 & 20.8 \\
\hline \multirow{3}{*}{ Animal involved } & Dog & 21 & 87.5 \\
\hline & Cat & 2 & 8.3 \\
\hline & Monkey & 1 & 4.2 \\
\hline \multirow{2}{*}{ Type of animal } & Stray & 18 & 75 \\
\hline & Pet & 6 & 25 \\
\hline \multirow{2}{*}{ Provocation status of the animal } & Provoked & 19 & 79.2 \\
\hline & Unprovoked & 5 & 20.8 \\
\hline \multirow{2}{*}{ Site of bite } & Lower limb & 18 & 75 \\
\hline & Upper limb & 6 & 25 \\
\hline \multirow{3}{*}{ Nature of bite } & Bite & 14 & 58.3 \\
\hline & Scratch & 9 & 37.5 \\
\hline & Lick & 1 & 4.2 \\
\hline \multirow{2}{*}{ Wound class* } & Class I & 10 & 41.7 \\
\hline & Class II & 14 & 58.3 \\
\hline \multirow{4}{*}{ Immediate wound management } & Washed with soap and water & 16 & 66.7 \\
\hline & Applied oil & 2 & 8.3 \\
\hline & Applied turmeric & 2 & 8.3 \\
\hline & Did not do anything & 4 & 16.7 \\
\hline \multirow{3}{*}{ Work lost by bite victim (in days) } & $<3$ & 12 & 50 \\
\hline & $3-7$ & 8 & 33.3 \\
\hline & $>7$ & 4 & 16.7 \\
\hline
\end{tabular}

*No animal bite wound, belonged to Class III

Nearly $88 \%(131 / 156)$ of the respondents knew that death can occur following animal bite. Among them only $19 \%$ $(25 / 131)$ could attribute the cause of death following animal bite. However, nearly $52 \%(68 / 131)$ of the respondents could not attribute the cause of death despite being aware of death following animal bite. All the respondents who were aware of death following animal bite (131) knew that the death could be prevented. All the respondents (156) were aware of the importance of initiating necessary immunization immediately following an animal bite and its free availability in Government Hospitals (GH), Pondicherry. Majority $(82 / 156,63 \%)$ of respondents opined that nothing should be done to the wound immediately following animal bite. Only one third (52/156) of the respondents were aware of washing the wound with soap and water. However, nearly $6.4 \%$ $(10 / 156)$ of the respondents believed that it was important to apply turmeric or chilli powder over the wound caused by animal bite.

A total of $24(3.52 \%, 24 / 682)$ members in 156 households had positive history of animal bite any time in the past. The last one year animal bite incidence was found to be $0.87 \%(6 / 682)$.

Majority of animal bite victims were males (79.2\%, 19/24) and belonged to Kuppusamy's socio-economic class V $(96 \%, 23 / 24)$. Majority of the cases of animal bites were because of dog bites $(88 \%, 21 / 24)$, stray animals $(75 \%, 18 / 24)$ and bites following provocation of animal (79\%, 19/24). Majority of the animal bite wounds belonged to Class II $(58.3 \%, 14 / 24)$, involved lower limb $(75 \%, 18 / 24)$ and were mostly because of bites by animal $(58.3 \%, 14 / 24)$. All the animal bite victims had received rabies immunization within 24 hours of bite and had completed the post exposure prophylaxis course. However, only two third of the victims had cleaned the animal bite wound with soap and water immediately following the bite. Few individuals $(16.6 \%, 4 / 24)$ had applied oil or turmeric over the wound. Nearly $17 \%$ (4/24) of the animal bite victims had lost more than 7 days of work (Table 2).

\section{DISCUSSION}

In our study, majority (88\%) of the respondents were aware that death can occur following animal bite. However, only one fifth of them $(25 / 131,19 \%)$ could name the disease rabies as the cause for death. Although subjects were aware of the consequences, there awareness on disease causation was poor. Higher proportion of individuals were reported to be aware of the disease Rabies compared to our study by Valekar et al $(61 \%)^{8}$ and Ichhpujani et al $(68 \%){ }^{7}$ In view of the above, awareness generation on rabies is an important priority to be considered in this population. 
Knowledge about correct wound management was found to be low among respondents in our study. Only one third of the respondents had correct knowledge about toileting wound with soap and water. Similar finding was reported by Singh and Choudhary from Gujarat $(31 \%)^{6}$ and Ichhpujani et al from a WHO sponsored multicentre study $(39 \%){ }^{7}$ However, Valekar et al from Maharasthra reported higher proportion $(45 \%)$ of respondents being aware of correct wound toileting practice with soap and water. ${ }^{8}$ Different studies from India also reported belief on local application of chillies, oil, turmeric etc. over wound similar to our study. ${ }^{4,5}$ Hence, awareness regarding correct first aid measures for the wound care following animal bite should be strengthened among the general population.

It is encouraging to note that all the study participants in our study were aware of immediate initiation of vaccination with anti-rabies vaccine following animal bite and the vaccine availability at government hospitals free of cost. However, comparatively lesser proportion of respondents were aware of anti-rabies vaccine in studies reported by Valekar et al $(95 \%),{ }^{8}$ and Singh and Choudhary (87\%). ${ }^{6}$ Only $55 \%$ of the respondents from an urban slum of Pune were aware of the importance of vaccine in prevention of rabies. ${ }^{9}$ In a study from rural Maharasthra nearly two third of the respondents felt that the anti-rabies vaccine was unaffordable by them. ${ }^{4}$

The annual incidence of animal bite in the present study was found to be $0.87 \%$ which is lower than the WHO sponsored multicentre study in India by Sudarshan et al $(1.7 \%) .^{5}$ A study from rural Tamil Nadu reported period prevalence of any animal bite, which included snakes, centipedes and scorpion also, to be 81.8 per 1000 population. ${ }^{10}$ The period prevalence specifically for $\mathrm{dog}$ bite alone was 22.2 per 1000 population in the same study.

Majority of the animal bite victims in our study were male similar to the report by Ichhpujani et al. ${ }^{11}$ In our study, majority of the animal bite cases (79\%) were because of dogs, similar to the study by Ichhpujaniet al $(92 \%)^{11}$ and Sudharshan et al $(91.5 \%) .^{5}$ Majority of the animal bite cases in our study was provoked bites in contrast to the findings by Ichhpujani et al $(63 \%)^{11}$ and Venkatesan et al $(80 \%)^{10}$ who independently reported that majority of the animal bites were without provocation. Majority $(58 \%)$ of the animal bite wounds in our study belonged to Class II as per WHO classification. Similar finding was reported by Rasania et al from Delhi. ${ }^{12}$ However, Class III wounds were reported to be more common in two independent studies by Ichhpujani et $\mathrm{al}^{11}$ and Vyas et al. Similarto our study Ichhpujani et al, ${ }^{11}$ Vyas et $\mathrm{al}^{13}$ and Venkatesan et $\mathrm{al}^{10}$ also reported involvement of lower limbs in majority of animal bite cases. All the individuals in our study reported to the health care facility immediately following animal bite, whereas only $63 \%$ of the cases reported to approach health care facility in a study by Shetty et al. ${ }^{14}$ The average time interval between exposure to animal bite and availing hospital care was reported to be 32 hours in a study from Gujarat. ${ }^{13}$ All the animal bite victims completed the post exposure prophylaxis in our study whereas only $80 \%$ of the victims had completed the rabies prophylaxis as reported by by Rasania et al. ${ }^{12}$ Contrast to cent percent in our study, only $88 \%$ of the people with animal bite had received treatment as reported in a study from rural Maharasthra. ${ }^{8}$ In our study, nearly two third of the victims had washed the wound with soap and water following animal bite. Similar finding was reported by Ichhpujani et $\mathrm{al}^{11}$ and Venkatesan et $\mathrm{al}^{10}$ on wound care following animal bite. The first aid measure with soap and water was adopted only by $3.6 \%$ of victims from a study in Pune. ${ }^{14}$ In a study from Gujarat, though $72 \%$ of the people had adopted pre-hospital care practice only $6 \%$ had washed the wound with soap and water following animal bite. ${ }^{13}$ About $17 \%$ of the individuals in our study reported to have applied oil or turmeric over wound. Ichhpujani et al also reported that nearly $11 \%$ of the animal bite victims had applied turmeric, salt, chillies, paste of leaves etc. over their wound. ${ }^{11}$ However, Vyas et al reported that nearly two third of the individuals had practiced local application of turmeric, oil, chillies, wheat flour etc. over wound. ${ }^{13}$ Local application over wound was also found to be prevalent $(37 \%)$ in a WHO sponsored national multicentre study by Sudharsan et al. ${ }^{5}$

In our study four individual $(16.7 \%)$ had lost more than seven days of work. Since majority of the animal bite victims were male and belonged to Kuppusamy's socioeconomic class $\mathrm{V}$, loss of working days was expected to have negative impact on the economic as well as living standard of the households pushing them further into poverty.

Steps were taken to decrease the social desirability bias by ensuring privacy and making the study participants comfortable before collecting information from them. However, the results could still be influenced by some amount of social desirability bias as the study subjects were personally interviewed. Sampling was based on feasibility, thus the study results cannot be generalized to whole of Pondicherry. However, our study provided an insight into the awareness and practice of the population regarding wound management following animal bites. Further research need to be carried out with a larger sample to explore the factors affecting poor wound care knowledge and practice. However, it was encouraging to note that $100 \%$ of the study participants were aware regarding the importance and availability of anti-rabies vaccine in government hospital free of cost and they too took anti-rabies vaccine following dog bite.

\section{CONCLUSION}

Knowledge and practice on wound management varies among the studied population. Health education should be strengthened on certain aspects like disease causation, 
wound care following animal bite and before coming in contact with a health facility to this population.

Funding: No funding sources

Conflict of interest: None declared

Ethical approval: The study was approved by the Institutional Ethics Committee

\section{REFERENCES}

1. Wandeler AI, Matter HC, Kappeler A, Budde A. The ecology of dogs and canine rabies: a selective review. Rev Sci Tech Int off Epizoot 1993;12(1):51-71.

2. Park K. Park's text book of preventive and social medicine. 22nd ed. Jabalpur: Banarsidas-Bhanot; 2013.

3. Kakrani VA, Jethani S, Bhawalkar J, Dhone A, Ratwani K. Awareness About Dog Bite Management In Rural Population. Indian J Community Heal 2013;25(3):304 - 308.

4. WHO | Animal bites [Internet]. WHO [cited 2015 Mar 25]; Available from: http://www.who.int/mediacentre/factsheets/fs373/en /

5. Sudarshan MK, Mahendra BJ, Madhusudana SN, Ashwoath Narayana DH, Rahman A, Rao NSN, et al. An epidemiological study of animal bites in India: results of a WHO sponsored national multicentric rabies survey. $J$ Commun Dis 2006;38(1):32-9.

6. Singh U, Choudhary S. Knowledge, Attitude, Behaviour and Practice Study on Dog-Bites and Its Management in the Context of Prevention of Rabies in a Rural Community of Gujarat. Indian $\mathbf{J}$ Community Med. 2005;30(3):81.

7. Ichhpujani RL, Chhabra M, Mittal V, Bhattacharya D, Singh J, Lal S. Knowledge, attitude and practices about animal bites and rabies in general community- -a multi-centric study. J Commun Dis 2006;38(4):355-61.

8. Valekar S, Kshirsagar M, Ashturkar M, Mhaske M, Chawla P, Fernandez K. A cross-sectional study of awareness regarding dog bite and its management in rural community of Maharashtra. Int J Community Med Public Heal. 2014;1(1):8.

9. Prakash M, Bhatti VK, Venkatesh G. Rabies menace and control - An insight into knowledge, attitude and practices. Med J Armed Forces India. 2013;69(1):57-60.

10. Murugan V, Dongre AR, Ganapathy K. An Epidemiological Study of Animal Bites and Envenomings in a Rural District of Tamilnadu, India. Online J Health Allied Scs. 2014;13(4):4.

11. Ichhpujani RL, Mala $C$, Veena $M$, Singh J, Bhardwaj M, Bhattacharya D, et al. Epidemiology of animal bites and rabies cases in India. A multicentric study. J Commun Dis. 2008;40(1):2736.

12. Rasania SK, Bhalla S, Khandekar J, Pathi S, Matta S, Singh S. Post exposure management of animal bite cases attending a primary health center of Delhi. J Commun Dis. 2004;36(3):195-8.

13. Vyas S, Gupta K, Bhatt G, Tiwari H. Animalbite management practices: Study at three municipal corporation hospitals of Ahmedabad. National Journal of Community Medicine. 2010;1(2):75-8.

14. Shetty RA, Chaturvedi S, Singh Z. Profile of animal bite cases in Pune. J Commun Dis. 2005;37(1):6672.

Cite this article as: Naik BN, Sahu SK, Ganesh KS. Wound management and vaccination following animal bite: a study on knowledge and practice among people in an urban area of Pondicherry, India. Int $\mathbf{J}$ Community Med Public Health 2015;2:501-5. 